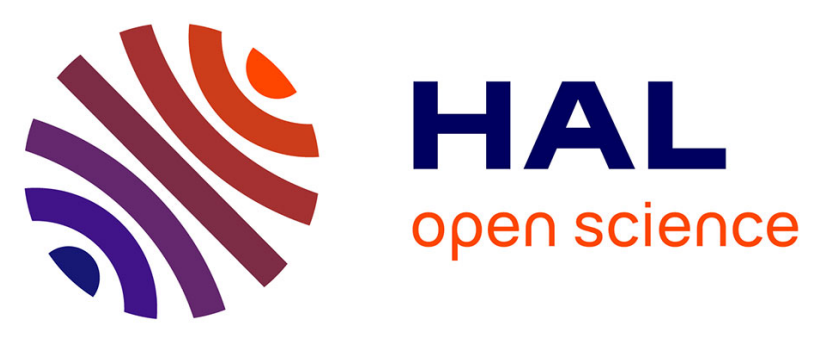

\title{
PTEN-regulated AKT/FoxO3a/Bim signaling contributes to Human cell glioblastoma apoptosis by platinum-maurocalcin conjugate
}

Sonia Aroui, Lucie Dardevet, Feten Najlaoui, Meriem Kammoun, Amel Laajimi, Hamadi Fetoui, Michel de Waard, Abderraouf Kenani

\section{To cite this version:}

Sonia Aroui, Lucie Dardevet, Feten Najlaoui, Meriem Kammoun, Amel Laajimi, et al.. PTENregulated AKT/FoxO3a/Bim signaling contributes to Human cell glioblastoma apoptosis by platinummaurocalcin conjugate. International Journal of Biochemistry and Cell Biology, 2016, 77, pp.15 - 22. 10.1016/j.biocel.2016.05.013 . pasteur-01404046

\section{HAL Id: pasteur-01404046 \\ https://hal-riip.archives-ouvertes.fr/pasteur-01404046}

Submitted on 28 Nov 2016

HAL is a multi-disciplinary open access archive for the deposit and dissemination of scientific research documents, whether they are published or not. The documents may come from teaching and research institutions in France or abroad, or from public or private research centers.
L'archive ouverte pluridisciplinaire HAL, est destinée au dépôt et à la diffusion de documents scientifiques de niveau recherche, publiés ou non, émanant des établissements d'enseignement et de recherche français ou étrangers, des laboratoires publics ou privés. 


\section{Accepted Manuscript}

Title: PTEN-regulated AKT/FoxO3a/Bim signaling contributes to Human cell glioblastoma apoptosis by platinum-maurocalcin conjugate

Author: Sonia Aroui Lucie Dardevet Feten Najlaoui Meriem Kammoun Amel Laajimi Hamadi Fetoui Michel De Waard

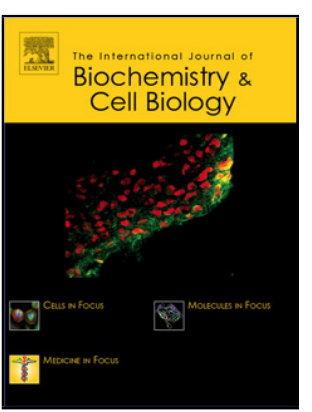
Abderraouf Kenani

PII:

DOI:

Reference:

S1357-2725(16)30119-4 http://dx.doi.org/doi:10.1016/j.biocel.2016.05.013

To appear in: BC 4859

Received date: The International Journal of Biochemistry \& Cell Biology

Revised date: 24-2-2016

Accepted date:

Please cite this article as: Aroui, Sonia., Dardevet, Lucie., Najlaoui, Feten., Kammoun, Meriem., Laajimi, Amel., Fetoui, Hamadi., Waard, Michel De., \& Kenani, Abderraouf., PTEN-regulated AKT/FoxO3a/Bim signaling contributes to Human cell glioblastoma apoptosis by platinum-maurocalcin conjugate.International Journal of Biochemistry and Cell Biology http://dx.doi.org/10.1016/j.biocel.2016.05.013

This is a PDF file of an unedited manuscript that has been accepted for publication. As a service to our customers we are providing this early version of the manuscript. The manuscript will undergo copyediting, typesetting, and review of the resulting proof before it is published in its final form. Please note that during the production process errors may be discovered which could affect the content, and all legal disclaimers that apply to the journal pertain. 
PTEN-regulated AKT/FoxO3a/Bim signaling contributes to Human cell glioblastoma apoptosis by platinum-maurocalcin conjugate

Sonia Aroui ${ }^{\mathrm{a}^{*}}$, Lucie Dardevet ${ }^{\mathrm{b}}$, Feten Najlaoui ${ }^{\mathrm{c}}$, Meriem Kammoun ${ }^{\mathrm{a}}$, Amel Laajimi $^{\mathrm{a}}$, Hamadi Fetoui ${ }^{\mathrm{d}}$, Michel De Waard ${ }^{\mathrm{b}, \mathrm{e}, \mathrm{f}},{ }^{\text {Abderraouf Kenani }}{ }^{\mathrm{a}}$

a Laboratoire de Biochimie, Unité de recherche UR 12ES08 "Signalisation Cellulaire et Pathologies" Faculté de Médecine de Monastir, 5019 Monastir, Tunisia.

${ }^{b}$ Inserm UMR1087/CNRS UMR6291, Institute of Thorax, LabEx Ion Channels, Science and Therapeutics, 44007 Nantes Cedex 1, France.

'Institute Pasteur of Tunis, Laboratory of venins and therapeutic biomolecules, LR11IPT08,13, 1002, Tunis, Tunisia.

'Laboratory of Toxicology; Microbiology and Environmental Health, UR11ES70, Sciences Faculty of Sfax, University of Sfax BP1171, 3000 Sfax, Tunisia.

e University of Nantes, 44007 Nantes, France.

fSmartox Biotechnology, 570 Rue de la Chimie, 38400 Saint-Martin d'Hères, France. 


\begin{abstract}
A previous report has shown that a chimera between a platinum complexing agent (1) and the cell penetrating peptide maurocalcin, synthesized with D-amino acids, (DMCa), termed Pt-1-DMCa, is a highly successful anticancer compound that works by targeting the intracellular redox system in glioblastoma (GBM) cells. However, the detailed cellular mechanism whereby the conjugate specifically kills tumor cells remains unclear. Herein, we show that Pt-1-DMCa induces apoptosis in Human U87 GBM cells through reactive oxygen species (ROS)-dependent modulation of the PI3K/AKT/FoxO3a signalling pathway. First, we found that Pt-1-DMCa treatment of these cells induces inhibition of AKT and nuclear accumulation of FoxO3a thereby facilitating transcription of the target genes Bim and PTEN. Modulation of the AKT/FoxO3a/Bim signaling pathway by RNA interference confirms that these signaling events are critical for Pt-1-DMCa-induced apoptosis of U87 GBM cells. Furthermore, we reveal that FoxO3a-mediated up-regulation of PTEN exerts an additional inhibitory effect on the AKT survival pathway. Thus, our results demonstrate that the conjugate can induce ROS-dependent FoxO3a-mediated apoptosis in U87 cells through PTEN-mediated inhibition of the PI3K/AKT survival axis. Our results help elucidate the molecular mechanisms underlying Pt-1-DMCa-induced cell death in U87 GBM cells and support a theoretical basis for future applications of the MCa peptide.
\end{abstract}




\section{Introduction}

Bypassing cellular membranes represents a main obstacle in current drug progression. Cellpenetrating peptides (CPP) are considered as molecular vectors that enter cells and can transport a large variety of bioactive molecules, such as drugs, peptides, proteins, oligonucleotides/cDNA/RNA, and nanoparticles (Margus et al., 2015; Ram et al., 2008). As such, CPP open the gate to many new therapeutic, diagnostic and biotechnological applications. L-maurocalcin (L-MCa), a disulfide-bridged constrained peptide, initially isolated from the venom of the scorpion Scorpio maurus palmatus, turned out to be a potent CPP performing in some cases better than some efficient popular CPP (Aroui et al., 2009; Perret et al., 2015; Ram et al., 2008). In one such application, we have previously reported that covalently coupling a platinum chelating agent to D-MCa to create a new complex termed Pt-1-DMCa, improves platinum delivery into cancer cells and kills U87 glioblastoma (GBM) cells through the induction of apoptosis (Aroui et al., 2015). This effect appears to involve intracellular oxidative stress, decreased levels of phosphorylated AKT and ERK and enhanced p53 phosphorylation. In the present study, we decided to decipher in more details the mechanisms underlying the Pt-1-DMCa-induced cell apoptosis. A better understanding of the downstream cellular targets of Pt-1-DMCa was focused on the Forkhead box O (FoxO) family which has been highlighted as an important transcriptional regulator of crucial proteins implicated in apoptosis.

Prior studies have revealed that the FoxO family is linked to different cellular activities, like differentiation, proliferation, defense against oxidative stress, autophagy and apoptosis (Lam et al., 2006; van der Vos et al., 2012). Recently, it was found that these transcription factors are also deregulated in multiple diseases, including cancer, i.e. breast cancer, prostate cancer and leukemia (Yang and Hung, 2011). In mammals, there are four highly related factors designed FoxO1/FKHR/FoxO1a, FoxO3/FKHRL1/FoxO3a, FoxO4/AFX and FoxO6 (Arden, 2006) which can be posttranslationally regulated by various signaling molecules, such as AKT which acts as an important upstream regulator (Calnan and Brunet, 2008). It has been reported earlier that AKT directly phosphorylates the FoxO family of proteins, resulting in FoxO's nuclear exclusion, cytoplasmic degradation, and ultimately tumor promotion (LoPiccolo et al., 2008; Yang and Hung, 2011). Importantly, FoxO transcriptional repression and degradation have been correlated with chemotherapy resistance in various cancers. By contrast, enhanced FoxO transcription activity is needed to promote apoptosis and cell cycle arrest in numerous tumors (Boreddy et al., 2011). Thus, FoxO has been shown to be a pivotal factor influencing the efficacy of a range of chemotherapeutic drugs. Reactivation of FoxO activity based on its tumor suppressor properties is advised as an attractive therapeutic 
strategy for tumor treatment (Yang et al., 2010; Yang and Hung, 2009). PI3K/AKT signaling has been delineated to be commonly deregulated in various cancers, particularly in GBM (Altomare and Testa, 2005; Roy et al., 2002). Therefore, exploration of the effects of Pt-1DMCa on this signalling pathway and its involvement in apoptosis is of great significance for future clinical applications of this conjugate.

In this study, we demonstrate that Pt-1-DMCa produces its pro-apoptotic effect through modulation of the PI3K/AKT/FoxO3a signalling hub in U87 GBM cells. We also present clear evidence that the conjugate inhibits the PI3K/AKT survival pathway in a reactive oxygen species (ROS)-dependent pathway. In addition, inhibition of AKT led to the activation of FoxO transcription factors and enhanced the expression of the target genes Bim and PTEN. As a result, Bim was shown to promote Pt-1-DMCa-induced apoptosis, and PTEN amplified the pro-apoptotic effect of Pt-1-DMCa by inhibiting the AKT/FoxO3a/Bim signaling pathway.

\section{Materials and Methods}

Reagents and antibodies

LY294002 was obtained from Invitrogen (Madison, WI, USA). N-acetyl-L-cysteine (NAC) and DAPI were purchased from Sigma-Aldrich (St. Louis, MO, USA). For Western blotting, the antibodies against $\beta$-actin, FoxO3a and $\mathrm{p}$-FoxO3a $\left(\mathrm{Ser}^{253}\right)$ were purchased from Santa Cruz Biotechnology Inc. (CA, USA). Antibodies recognizing cleaved caspase 9, cleaved PARP, p-Src $\left(\right.$ Tyr $\left.^{416}\right)$, Src, p-p85 (Tyr $\left.{ }^{458}\right)$, p85, p-PDK1 (Ser $\left.{ }^{241}\right)$, PDK1, p-AKT $\left(\right.$ Thr $\left.^{308}\right)$, AKT, p-FoxO1 $\left(\right.$ Ser $\left.^{256}\right)$, FoxO1, PTEN, Bim and p-PTEN (Ser ${ }^{380}$ ) were purchased from Cell Signaling (Beverly, MA, USA).

Plasmids transient transfection.

Approximately $10^{5}$ cells were plated into six-well plate $24 \mathrm{hrs}$ before transfection experiments to allow cell attachment. At $50 \%$ confluency, cells were transfected with indicated plasmids by lipofectamine 2000 reagent (Invitrogen), according to the manufacturer's protocol. Briefly, about $4 \mu \mathrm{g}$ plasmids were transfected into cells together with $5 \mu \mathrm{L}$ lipofectamine 2000 reagent per well. At 24 hrs after transfection, cells were treated as needed. 
Small interfering RNAs

AKT1 siRNA (5'-AAGGAGGGUUGGCUGCACAAA-3'); FOXO3a siRNA (5'-AAUGUGACAUGGAGUCCAUUA-3'); Bim siRNA (5'-AAGGUAGACAAUUGCAGCCUG-3'); PTEN SiRNA (5'GACUUGAAGGCGUAUACAGTT-3') and the control siRNA (5'-UUCUCCGAACGUGUCA-CGUTT$\left.3^{\prime}\right)$ were chemically synthesized. Cells cultured in six-well plates were transfected with 100 pM siRNA by lipofectamine 2000 according to the guidelines as described above. Cells were then subjected to further treatment as described in the text.

Cell lines and culture

Glioma U87 cells were purchased from the American Type Culture Collection (Rockville, MD, USA) and maintained in Dulbecco's modified Eagle's medium (DMEM, Invitrogen, Paisley, Scotland), supplemented with $10 \%$ fetal bovine serum (FBS) and 10,000 units/mL streptomycin and penicillin. Cells were incubated at $37^{\circ} \mathrm{C}$ in a humidified atmosphere containing $5 \% \mathrm{CO}_{2}$ and were monitored routinely. All cell lines were discarded after 20 passaging and new lines were propagated from the frozen stocks.

\section{$R T-P C R$}

Total RNA was isolated using the Trizol reagent (Life Technologies, Grand Island, NY, USA) according to the manufacturer's instructions. The cDNA was synthesized using M-MLV reverse transcriptase, oligo dT primer and dNTPs (Sigma Aldrich, St. Louis, MO, USA), and was subjected to PCR with specific primers. The sequences of the sense and antisense primers for PTEN (forward: 5'-CCAATGTTCAGTGGCGGAACT-3'; reverse: 5'GAACTTGTCTTCCCGTCGTGTG-3'), Bim (forward: 5'-GAGCCACAAGACAGGAGC-3'; reverse: 5' AAGGGCAATTCTGAGGGA-3') and GAPDH (forward: 5'-CATCTTCCAGGAGC-GAGATC-3'; reverse: 5'-GCTTGA-CAAAGTGGTCGTTG-3'). PCR products were analyzed by $1.2 \%$ agarose gel electrophoresis and the band intensities of each band were normalized to the corresponding GAPDH bands.

Immunofluorescence 
Cells were grown on coverslips into a six-well plate for $24 \mathrm{hrs}$ before treatment with $20 \mu \mathrm{M}$ Pt-1-DMCa or PBS solution for another $24 \mathrm{hrs}$. Cells were then fixed in $4 \%$ paraformaldehyde and permeabilized with $0.1 \%$ Triton X-100 solution for $20 \mathrm{~min}$. After washing with PBS two times, the samples were blocked with $5 \%$ BSA solution for $30 \mathrm{~min}$ at room temperature. Then, slides were incubated with the indicated primary antibodies overnight at $4^{\circ} \mathrm{C}$ or $1 \mathrm{hr}$ at room temperature. Finally, cells were incubated with FITC- or Cy3-labeled secondary antibodies for $45 \mathrm{~min}$ at room temperature, followed by counterstaining with DAPI solution and visualized using a Zeiss fluorescent microscope.

\section{Cell count and flow cytometry analysis}

Cells grown in six-well plates were treated or not with $20 \mu \mathrm{M}$ Pt-1-DMCa for $24 \mathrm{hrs}$. Both adherent and floating cells were collected after treatment. After centrifugation, the pellet was washed twice with cold PBS and fixed by chilled ethanol overnight. Thereafter, the cells were washed with PBS and incubated with $500 \mu \mathrm{L}$ propidium iodide (PI) solution $(50 \mu \mathrm{g} / \mathrm{mL})$. After 30 min incubation in the dark, analysis was performed with a flow cytometer (FACS Calibur, BD Biosciences). Fluorescence emitted from the propidium iodide-DNA complex was estimated for a minimum of 10,000 cells per sample and analyzed using Cell Quest Alias software (BD Biosciences, San Jose, CA, USA. The percentage of cells in different cell cycle phases was evaluated. Cells with DNA content less than that of the G1 phase (sub-G1 peak) were considered as apoptotic cells.

\section{Immunoblotting}

To prepare lysates, cells were incubated for the indicated time and concentration of Pt-1DMCa, collected after trypsinization and washed twice with cold PBS. Total cell lysates were scrapped in ice-cold lysis buffer (10 mM Tris pH 7.5, 0.5 mM EDTA pH 8.0, 0.5 mM DTT, 0.5\% CHAPS, $10 \%$ glycerol) supplemented with a cocktail of protease inhibitors. Specifically, nuclear fractions were obtained using the NE-PER nuclear/cytoplasmic extraction kit. Mitochondria were fractionated using the Mitochondria Isolation Kit for Mammalian Cells (Thermo Fisher Scientific, Rockford, IL, USA). Proteins in each sample were determined using the DC Protein Assay (Bio-Rad) according to the manufacturer's specifications. After normalization, equal amounts of proteins were fractionated on 8-15\% SDS-PAGE gels. The proteins were then transferred overnight or $2 \mathrm{hrs}$ at $4^{\circ} \mathrm{C}$ to a polyvinylidene difluoride (PVDF) membrane (Amersham Hybond ${ }^{\mathrm{TM}}$-P, GE Healthcare, Buckinghamshire, UK) and incubated with the indicated primary antibodies and corresponding HRP conjugated secondary 
antibodies. The immunoreactive bands were visualized by chemiluminescence according to the manufacturer's recommendations (ECL, Amersham Pharmacia (Amersham Hybond ${ }^{\mathrm{TM}}-\mathrm{P}$, GE Healthcare, Buckinghamshire, UK). The ECL staining was quantified by densitometry with ImageJ software (National Institutes of Health, USA).

\section{ChIP assay}

ChIP assays were carried out using the Simple ChIP Enzymatic Chromatin IP Kit (Thermo Scientific, Rockford, IL, USA) as described by the manufacturer's instructions. Briefly, cells were fixed with $1 \%$ formaldehyde in order to preserve the protein-DNA interactions occurring in the nuclei. The cross-linked chromatin was then extracted from cells using buffers provided in the ChIP kit and then digested into small fragments using micrococcal nuclease for $20 \mathrm{~min}$ at $37^{\circ} \mathrm{C}$. The cross-linked chromatin was then subjected to immunoprecipitation using $2 \mathrm{mg}$ of foxo3a antibody and normal rabbit immunoglobulin $\mathrm{G}$ antibody overnight at $4^{\circ} \mathrm{C}$ with gentle rotation. The complexes of interest were captured by ChIP-Grade Protein $\mathrm{G}$ agarose beads for $2 \mathrm{hrs}$ at $4^{\circ} \mathrm{C}$ with gentle rotation. Following thorough washing, bound DNA fragments were eluted and analyzed by subsequent PCR using primers for Bim and PTEN as follows: Bim: forward 5'-AGGCAGAACAGGAGGAGA-3' ; reverse 5'AACCCGTTTGTA-AGAGGC-3' and PTEN: forward 5'-GCATTTCCGAATCAGCTCTCT-3'; reverse: 5'- CCAAGTGACTTATCTCTGGTCTGAG-3'.

Statistical analyses

Quantitative analyses represented in histograms are expressed as mean \pm standard error of the mean (mean \pm SEM). All analyses were carried out with GraphPad Prism 6.0 for Windows (GraphPad Software, San Diego, CA, USA). Significant differences between the effects of the treatments were determined by one-way ANOVA, followed by Tukey's post hoc test for multiple comparisons with statistical significance of $p<0.05$.

\section{Results}

Pt-1-DMCa-induced apoptosis is associated with the SrC/PI3K/AKT/FoxO3a signaling pathway 
Our previous data had shown that $20 \mu \mathrm{M}$ Pt-1-DMCa induces apoptosis of GBM U87 cells through the activation of the extrinsic and intrinsic apoptosis pathways (Aroui et al., 2015). Here, we aimed at elucidating the underlying molecular mechanisms of this effect. We conducted experiments to explore whether Pt-1-DMCa could affect the AKT survival pathway in U87 cells. As shown in Figure 1A, we found that $20 \mu \mathrm{M}$ of Pt-1-DMCa timedependently inhibits the Src/PI3K/PDK1/AKT survival pathway in U87 cells. Significant reductions were observed for-Src (Tyr416) (72\%), p-PI3K (Tyr458) (p85; 83\%), p-PDK1 (Ser241) (67\%) and p-AKT (Thr308)evels (85\%) after 24 hrs incubation with $20 \mu \mathrm{M}$ Pt-1DMCa (Figure 1B). We therefore postulated that the FoxO family proteins may be regulated by Pt-1-DMCa-inhibited AKT since it is known that FoxO's play a very important role in cell cycle arrest and apoptosis in response to a decrease in p-AKT levels (Hussain et al., 2011; van Gorp et al., 2006).

In order to test this hypothesis, we immunoblotted the FoxO family proteins (FoxO1 and FoxO3a) for $20 \mu \mathrm{M}$ Pt-1-DMCa-treated cells and found that the conjugate consistently suppressed the phosphorylation of these proteins after $24 \mathrm{hrs}$ (Figure 2A). These data indicate that FoxO proteins may be activated when AKT function is inhibited by Pt-1-DMCatriggered dephosphorylation of AKT. To further substantiate this finding, we extracted cytoplasmic and nuclear fractions from U87 cells and immunoblotted for FoxO3a and pFoxo3a in both control and $20 \mu \mathrm{M}$ Pt-1-DMCa-treated cells ( $24 \mathrm{hrs}$ treatment). We found that the conjugate increases the nuclear levels of FoxO3a, while decreasing the cytoplasmic levels of the protein (Figure 2B). However, phosphorylated FoxO3a levels were mainly elevated in the cytoplasm and poorly present in the nucleus. In addition, immunofluorescence results (Figure 2C, D) also support the above conclusion that Pt-1DMCa induces accumulation of non-phosphorylated FoxO3a in the nucleus. Taken together, these results demonstrate that Pt-1-DMCa inhibits SrC/PI3K/PDK1/AKT signaling and activates FoxO family proteins in U87 GBM cells by promoting nuclear accumulation of the non-phosphorylated form of these proteins and decreasing their phosphorylation levels.

AKT/FoxO3a signaling is correlated with Pt-1-DMCa induced apoptosis in U87 cells

Since Pt-1-DMCa treatment inhibits Src/PI3K/PDK1/AKT signaling and activated FoxO proteins, we investigated the relationship between AKT and FoxO3a in Pt-1-DMCa-induced apoptosis of $U 87$ cells. As revealed in Figure 3A, upon AKT inhibition by $20 \mu \mathrm{M}$ Pt-1-DMCa, we found that the PI3K inhibitor LY294002 produces an enhanced decrease of the $\mathrm{p}$-AKT level. As expected, inhibiting AKT phosphorylation level further suppresses the phosphorylation of FoxO3a even with a $20 \mu \mathrm{M}$ Pt-1-DMCa treatment during $24 \mathrm{hrs}$.

Moreover, we attempted to determine the role of AKT/FoxO3a in Pt-1-DMCa-induced apoptosis of U87 cells (Figure 3B). Analysis of the apoptotic rate after silencing AKT with 
siRNA slightly enhances the apoptosis of U87 cells treated with $20 \mu \mathrm{M}$ Pt-1-DMCa $(32.4 \pm$ $4.0 \%$ instead of $27.1 \pm 2.0 \%$ in the absence of the AKT siRNA). In contrast, siRNA-mediated FoxO3a silencing markedly decreased the level of apoptosis in Pt-1-DMCa treated U87 cells $(16.7 \pm 2.1 \%$ instead of $27.0 \pm 3.0 \%$ in the absence of the FoxO3a siRNA) (Figure $3 \mathrm{C})$.Alone, The AKT siRNA or the FoxO3a didn't display an apoptotic effect in the same conditions $15.2 \pm$ $2 \%)$. These findings collectively demonstrate that Pt-1-DMCa induces apoptosis of U87 cells through regulation of the AKT/FoxO3a pathway.

Bim acts as a pivotal downstream factor of FoxO3a and thereby contributes to apoptosis

Increasing amount of FoxO3a in the nucleus should lead to increased binding on promoters that contain the adequate consensus sequence and in turn promote the expression of proteins involved in apoptosis and cell cycle, such as bim, puma, p27 and p21 (Tsai et al., 2007). Previously, we demonstrated that proteins of the $\mathrm{Bcl}-2$ family are critical regulators of Pt-1-DMCa-induced apoptosis (Aroui et al., 2015). We thus performed chromatin immunoprecipitation (ChIP) experiments to examine whether Pt-1-DMCa could enhance the binding of FoxO3a to the Bim promoter in order to promote Bim transcription. As shown in Figure 4A and B, Pt-1-DMCa treatment in U87 cells enhances FoxO3a binding to the Bim promoter thereby raising transcription levels in a time-dependent manner (Figure 4C). In addition, Western blot data also indicate that Pt-1-DMCa treatment time-dependently increases the expression of the Bim protein (Figure 4D). To explore whether Bim participates in Pt-1-DMCa-induced apoptosis of U87 cells, an immunostaining assay was performed in these cells (Figure 4E). The results corroborate the finding that Pt-1-DMCa induces the colocalization of Bim with the mitochondria and thus has the potential to activate the apoptotic cascade. To further support the role of Bim in apoptosis, we knocked down the expression of Bim with siRNA in cells treated with Pt-1-DMCa and found that Bim silencing considerably blocked Pt-1-DMCa-induced cleavage of PARP and activation of caspase-9 (Figure 4F). Finally, a protective apoptotic rate was observed in Bim-silenced U87 cells after treatment of the cells by $20 \mu \mathrm{M}$ of Pt-1-DMCa during $24 \mathrm{hrs}$. In this case, a near $50 \%$ reduction of the apoptotic rate was observed as compared to U87 cells transfected with scrambled control siRNA (Figure 4G). Thus, the data indicate that Pt-1-DMCa-mediated apoptosis is largely due to Bim, a pivotal downstream factor of FoxO-induced transcriptional activation.

FoxO3a-upregulated PTEN expression is involved in regulating Pt-1-DMCa-induced changes in the AKT/FoxO3a/Bim signaling pathway 
In our experiments, we surprisingly found that the Pt-1-DMCa-induced FoxO3a also binds to the promoter of the PTEN gene in U87 GBM cells as demonstrated by the ChIP assay (Figure $5 A, B)$. Additional results indicate that FoxO3a directly facilitates PTEN transcription rather than blocking its degradation, since a time-dependent increase of PTEN mRNA level was observed after Pt-1-DMCa treatment (Figure 5C). Moreover, the PTEN protein levels increase in a time-dependent manner after Pt-1-DMCa treatment as witnessed by Western blotting (Figure 5D). To clarify whether upregulation of PTEN could indeed affect the AKT/FoxO3a signaling pathway, we knocked down PTEN expression using the corresponding siRNA. As shown in Figure 5E,F, PTEN knockdown reverses the changes elicited before by Pt-1-DMCa in U87 cells in terms of PARP cleavage and Bim upregulation and loss of phosphorylation level of $p$-AKT and p-FoxO3a. Thus, we conclude that Pt-1-DMCa-induced inhibition of AKT and the activation of FoxO3a/Bim as well as apoptosis are critically regulated by increased levels of PTEN.

Pt-1-DMCa -induced ROS are indispensable for AKT/FOXO3a/Bim-mediated apoptosis in U87 cells

Our previous work has identified ROS as an important factor in the induction of apoptosis in U87 cells (Aroui et al., 2015). We showed that Pt-1-DMCa treatment could induce an increased level of ROS in these cells. Thus, we conducted experiments to elucidate whether ROS were involved in Pt-1-DMCa-induced apoptosis of U87 cells. To explore the possible link between ROS and AKT/FOXO3a/Bim-mediated apoptosis, we eliminated ROS in cells treated with $20 \mu \mathrm{M}$ Pt-1-DMCa for $24 \mathrm{hrs}$ using a widely used ROS scavenger, NAC, and found that depletion of ROS efficiently inhibited apoptosis induced by Pt-1-DMCa (Figure 6A). Furthermore, the effect of Pt-1-DMCa on the phosphorylation of AKT and Fox03a were completely reversed (Figure 6B). Altogether these results argue for a role of ROS in Pt-1DMCa-induced AKT/FOXO3a/Bim-mediated apoptosis in U87 GBM cells.

Discussion

GBM which refers to high-grade gliomas (grade IV) is one of the most common brain / central nervous system cancer in humans (Messali et al., 2014). Prognosis of GBM patients remains poor since the average life expectancy of these patients is 14 months and therefore remains under the current standard of care. It is therefore imperative to develop new treatment strategies to overcome GBM (24).

It is known that the ability of tumor cells to develop in number is determined not only by the rate of cell proliferation, but also by the rate of cell death. Apoptosis is a major process of 
cell death; agents that trigger apoptosis/cell death, in malignant cells, are promising therapeutic candidates for cancer. In this way, signal transduction pathways implicated in cell growth and apoptosis are potential targets for chemo-preventive agents. Nonetheless, the signaling pathways directing to apoptosis are complex and vary largely with the cell type involved (Picone et al., 2014). Elucidating the mechanisms of anti-tumor activity of new compounds will help the identification of the best candidates for chemo-preventive and therapeutic agents for various human cancers.

Numerous actual studies are meant to use a combination of apoptosis-inducing agents or an improvement of the uptake of these agents by using CPPs. In this aim, we have developed recently a new conjugate, Pt-1-DMCa, which is a promising candidate for reducing cell expulsion of the platinum and increase its efficiency in terms of apoptosis induction (Aroui et al., 2015).

In this study, we provide evidence that the AKT/FoxO3a/Bim/PTEN signaling axis is closely correlated with Pt-1-DMCa-induced apoptosis in U87 GBM cells. Altogether, our results suggest that Pt-1-DMCa inhibits Src/PI3K/PDK1/AKT signaling and activate FoxO proteins. FoxO family proteins have appeared as critical regulators that control many cellular activities through the implication of different genes and proteins in response to diverse stimuli (Carter and Brunet, 2007). It was shown that FoxO3a, one member of the FoxO family, is a main tumor suppressor in multiple cancers through transcriptional regulation of multiple proteins, including p21 ${ }^{\mathrm{Cip} 1}, \mathrm{p} 27^{\mathrm{Kip} 1}$, cyclin D1 and Bim (Essafi et al., 2005).

Here, we were intrigued by the effect of AKT on FoxO3a and its downstream targets after treatment by Pt-1-DMCa since AKT was demonstrated to be notably activated in multiple malignant tumors, such as glioma. Accordingly, understanding the molecular mechanisms of drugs targeting AKT could be important for treating cancer. Our data demonstrated that Pt1-DMCa inhibited AKT and its upstream regulator PI3K and PDK1 in a time-dependent manner. Meanwhile, inhibition of AKT by Pt-1-DMCa was shown to be directly related to the reduced phosphorylation level of FoxO3a, which resulted in its accumulation in the nucleus. These findings are consistent with studies describing that many chemotherapy drugs, such as $18 \beta$-glycyrrhetinic acid, isoflavone and paclitaxel modulate the AKT/FoxO3a signaling pathway in GBM cells and induce apoptosis (Sharma et al., 2012; Sunters et al., 2006; Sykes et al., 2011). It is well known that in cell survival process, AKT phosphorylates FoxO3a at $\mathrm{Thr}^{32}, \mathrm{Ser}^{256}$ and $\mathrm{Ser}^{319}$ and promotes its binding to 14-3-3 proteins, resulting in the retention of FoxO3a by 14-3-3 in the cytoplasm (Essafi et al., 2005). Contrarily, inhibition of the AKT activity induces a dephosphorylation of FoxO3a which in turn dissociates from 14-3-3 proteins in cytoplasm and localizes in the nucleus. This translocation induces FoxO3a key target genes that promote cell cycle arrest and apoptosis such as the pro-apoptotic protein $\mathrm{Bcl}$-2-interacting mediator of cell death (Bim) (Essafi et al., 2005) Accordingly, Pt-1-DMCa treatment could decrease 14-3-3 binding sites on FoxO3a proteins which explain the 
translocation of FoxO3a to the nucleus. This helps us to further explore the role of FoxO3a in the nucleus following treatment with Pt-1-DMCa in U87 GBM cells.

Bim is a potent pro-apoptotic $\mathrm{Bcl}-2$ protein with the capability to simultaneously bind and antagonize multiple anti-apoptotic Bcl-2 family members (such as $\mathrm{Bcl}-\mathrm{xL}$ and $\mathrm{Bcl}-2$ ) in mitochondria (O'Connor et al., 1998; Strasser et al., 2000). Therefore, we payed close attention to the role of Bim in the Pt-1-DMCa-mediated apoptosis in U87 GBM cells. Bim was also shown to be a direct target of FoxO3a (Strasser et al., 2000). In the present study, we demonstrate that activated FoxO3a could bind more efficiently to the promoter of Bim gene thereby facilitating Bim transcription. In parallel, an increase in Bim protein level was correlated with a shifting in subcellular localization from the cytoplasm to the mitochondria. Moreover, inhibition of Bim by an siRNA approach significantly attenuates the apoptotic effect of Pt-1-DMCa in U87 GBM cells. Collectively, these evidences suggest an essential role of Bim upregulation in Pt-1-DMCa-mediated apoptosis.

PTEN is frequently mutated in numerous cancers as it normally functions as a tumor suppressor to antagonize the effects of PI3K through its lipid phosphatase activity (Hollander et al., 2011; Salmena et al., 2008). Therefore, AKT activation is balanced by both PTEN and PI3K. From the data we noticed that Pt-1-DMCa inhibits the phosphorylation of Src and the p85 subunit of PI3K and its downstream effectors PDK1 and AKT. In addition, PTEN activity was shown to be upregulated by FoxO3a. Therefore, we hypothesized that Pt-1-DMCainduced activation of PTEN was involved in the regulation of the AKT/FoxO3a/Bim signaling pathway. We transfected cells with PTEN siRNA and discovered that Pt-1-DMCa-mediated modulation of the AKT/FoxO3a/Bim pathway was abrogated when PTEN was inhibited (Figure 5e). Therefore, we concluded that Pt-1-DMCa-induced PTEN regulation was associated with the AKT/FoxO3a/Bim pathway and apoptosis in U87 cells, which is consistent with the findings from other groups showing that PTEN directly regulates AKT/FoxO3a under various treatment conditions in cancer cells such as the metalloid trace element selenite (Luo et al., 2013), the hydrogen peroxide (Yang and Hung, 2009), berberine, a plant-derived isoquinoline alkaloid (Shukla et al., 2014). However, whether a positive feedback loop exists between PTEN and the AKT/FoxO/Bim signaling pathway, will require further investigation.

Our previous results have shown that ROS is a potential mediator of Pt-1-DMCa-induced apoptosis and its related signaling pathway in giloma cells (Aroui et al., 2015). To define the role of Pt-1-DMCa-induced ROS in the AKT/FoxO3a/Bim signaling pathway, we inhibited ROS production in U87 glioma cells and observed that the alterations in the AKT/FoxO3a/Bim pathway were inhibited. In addition, Pt-1-DMCa-induced apoptosis was repressed when cells were pretreated with a ROS scavenger. Thus, the Pt-1-DMCa-regulated PTEN/AKT/FoxO3a/Bim signaling pathway leading to apoptosis is critically modulated by ROS 
in U87 GBM cells. However, much work still needs to be done to clarify the relationship between ROS and Pt-1-DMCa modulated FoxO proteins. For example, we could show if FoxO proteins reduce the ROS level in cells by impairing the expression of genes with mitochondrial function rather than in the canonical SOD2-independent manner as shown by Schulze coworkers (Ferber et al., 2011).

In summary, the evidence presented in the current study demonstrates that the novel conjugate Pt-1-DMCa induces U87 GBM cell apoptosis by inhibiting the SrC/PI3K/AKT survival factors and activating FoxO proteins along with the targets Bim and PTEN. Activated FoxO3a bound more deeply to the Bim and PTEN promoters, thereby increasing their transcription and expression levels. Moreover, immunofluorescence and Western blot results both demonstrated enhanced of Bim translocation levels from the cytoplasm to the mitochondria. In addition to that, RNA interference experiments revealed that this process was essential for Pt-1-DMCa-induced apoptosis. Pt-1-DMCa induced PTEN further amplified this effect on the AKT/FoxO3a/Bim signaling pathway. Altogether, these findings help us elucidate the molecular effects of Pt-1-DMCa treatment and provide a theoretical basis for its future pharmacological application as a novel anticancer drug.

\section{References}

Altomare DA and Testa JR (2005) Perturbations of the AKT signaling pathway in human cancer. Oncogene 24(50): 7455-7464.

Arden KC (2006) Multiple roles of FOXO transcription factors in mammalian cells point to multiple roles in cancer. Exp Gerontol 41(8): 709-717.

Aroui S, Dardevet L, Ajmia WB, de Boisvilliers M, Perrin F, Laajimi A, Boumendjel A, Kenani A, Muller JM and De Waard M (2015) A Novel Platinum-Maurocalcine Conjugate Induces Apoptosis of Human Glioblastoma Cells by Acting through the ROS-ERK/AKT-p53 Pathway. Mol Pharm 12(12): 4336-4348.

Aroui S, Ram N, Appaix F, Ronjat M, Kenani A, Pirollet F and De Waard M (2009) Maurocalcine as a Non Toxic Drug Carrier Overcomes Doxorubicin Resistance in the Cancer Cell Line MDA-MB 231. Pharm Res 26(4): 836-845.

Boreddy SR, Pramanik KC and Srivastava SK (2011) Pancreatic tumor suppression by benzyl isothiocyanate is associated with inhibition of PI3K/AKT/FOXO pathway. Clin Cancer Res 17(7): 17841795.

Calnan DR and Brunet A (2008) The FoxO code. Oncogene 27(16): 2276-2288.

Carter ME and Brunet A (2007) FOXO transcription factors. Curr Biol 17(4): R113-114.

Essafi A, Fernandez de Mattos S, Hassen YA, Soeiro I, Mufti GJ, Thomas NS, Medema RH and Lam EW (2005) Direct transcriptional regulation of Bim by FoxO3a mediates STI571-induced apoptosis in BcrAbl-expressing cells. Oncogene 24(14): 2317-2329. 
Ferber EC, Peck B, Delpuech O, Bell GP, East P and Schulze A (2011) FOXO3a regulates reactive oxygen metabolism by inhibiting mitochondrial gene expression. Cell Death Differ 19(6): 968-979.

Hollander MC, Blumenthal GM and Dennis PA (2011) PTEN loss in the continuum of common cancers, rare syndromes and mouse models. Nat Rev Cancer 11(4): 289-301.

Hussain AR, Uddin S, Bu R, Khan OS, Ahmed SO, Ahmed M and Al-Kuraya KS (2011) Resveratrol suppresses constitutive activation of AKT via generation of ROS and induces apoptosis in diffuse large B cell lymphoma cell lines. PLoS One 6(9): e24703.

Lam EW, Francis RE and Petkovic M (2006) FOXO transcription factors: key regulators of cell fate. Biochem Soc Trans 34(Pt 5): 722-726.

LoPiccolo J, Blumenthal GM, Bernstein WB and Dennis PA (2008) Targeting the PI3K/Akt/mTOR pathway: effective combinations and clinical considerations. Drug Resist Updat 11(1-2): 32-50.

Luo H, Yang Y, J Duan J, Wu P, Jiang Q and Xu C (2013) PTEN-regulated AKT/FoxO3a/Bim signaling contributes to reactive oxygen species-mediated apoptosis in selenite-treated colorectal cancer cells Cell Death Dis 7 (4):e48.

Margus H, Arukuusk P, Langel U and Pooga M (2015) Characteristics of Cell-Penetrating Peptide/Nucleic Acid Nanoparticles. Mol Pharm 13(1): 172-179.

Messali A, Villacorta R and Hay JW (2014) A review of the economic burden of glioblastoma and the cost effectiveness of pharmacologic treatments. Pharmacoeconomics 32(12): 1201-1212.

O'Connor L, Strasser A, O'Reilly LA, Hausmann G, Adams JM, Cory S and Huang DC (1998) Bim: a novel member of the Bcl-2 family that promotes apoptosis. EMBO J 17(2): 384-395.

Perret P, Ahmadi M, Riou L, Bacot S, Pecher J, Poillot C, Broisat A, Ghezzi C and De Waard M (2015) Biodistribution, Stability, and Blood Distribution of the Cell Penetrating Peptide Maurocalcine in Mice. Int J Mol Sci 16(11): 27730-27740.

Picone P, Nuzzo D, Caruana L, Messina E, Scafidi V and Di Carlo M (2014) Curcumin induces apoptosis in human neuroblastoma cells via inhibition of AKT and Foxo3a nuclear translocation. Free Radic Res 48(12): 1397-1408.

Ram N, Weiss N, Texier-Nogues I, Aroui S, Andreotti N, Pirollet F, Ronjat M, Sabatier JM, Darbon H, Jacquemond V and De Waard M (2008) Design of a disulfide-less, pharmacologically-inert and chemically-competent analog of maurocalcine for the efficient transport of impermeant compounds into cells. J Biol Chem 283: 27048-27056.

Roy HK, Olusola BF, Clemens DL, Karolski WJ, Ratashak A, Lynch HT and Smyrk TC (2002) AKT protooncogene overexpression is an early event during sporadic colon carcinogenesis. Carcinogenesis 23(1): 201-205. 
Salmena L, Carracedo A and Pandolfi PP (2008) Tenets of PTEN tumor suppression. Cell 133(3): 403414.

Sharma G, Kar S, Palit S and Das PK (2012) 18beta-glycyrrhetinic acid induces apoptosis through modulation of Akt/FOXO3a/Bim pathway in human breast cancer MCF-7 cells. J Cell Physiol 227(5): 1923-1931.

Strasser A, Puthalakath H, Bouillet P, Huang DC, O'Connor L, O'Reilly LA, Cullen L, Cory S and Adams JM (2000) The role of bim, a proapoptotic BH3-only member of the Bcl-2 family in cell-death control. Ann N Y Acad Sci 917: 541-548.

Sunters A, Madureira PA, Pomeranz KM, Aubert M, Brosens JJ, Cook SJ, Burgering BM, Coombes RC and Lam EW (2006) Paclitaxel-induced nuclear translocation of FOXO3a in breast cancer cells is mediated by c-Jun NH2-terminal kinase and Akt. Cancer Res 66(1): 212-220.

Sykes SM, Lane SW, Bullinger L, Kalaitzidis D, Yusuf R, Saez B, Ferraro F, Mercier F, Singh H, Brumme KM, Acharya SS, Scholl C, Tothova Z, Attar EC, Frohling S, DePinho RA, Armstrong SA, Gilliland DG and Scadden DT (2011) AKT/FOXO signaling enforces reversible differentiation blockade in myeloid leukemias. Cell 146(5): 697-708.

Tsai KL, Sun YJ, Huang CY, Yang JY, Hung MC and Hsiao CD (2007) Crystal structure of the human FOXO3a-DBD/DNA complex suggests the effects of post-translational modification. Nucleic Acids Res 35(20): 6984-6994.

van der Vos KE, Gomez-Puerto C and Coffer PJ (2012) Regulation of autophagy by Forkhead box (FOX) O transcription factors. Adv Biol Regul 52(1): 122-136.

van Gorp AG, Pomeranz KM, Birkenkamp KU, Hui RC, Lam EW and Coffer PJ (2006) Chronic protein kinase $B$ (PKB/C-akt) activation leads to apoptosis induced by oxidative stress-mediated Foxo3a transcriptional up-regulation. Cancer Res 66(22): 10760-10769.

Yang JY, Chang CJ, Xia W, Wang Y, Wong KK, Engelman JA, Du Y, Andreeff M, Hortobagyi GN and Hung MC (2010) Activation of FOXO3a is sufficient to reverse mitogen-activated protein/extracellular signal-regulated kinase kinase inhibitor chemoresistance in human cancer. Cancer Res 70(11): 47094718.

Wang F, Wang YQ, Cao Q, Zhang JJ, Huang LY, Sang TT, Liu F, Chen SY (2013)

Hydrogen peroxide induced impairment of endothelial progenitor cell viability is mediated through a FoxO3adependant mechanism. Microvasc Res (90): 48-54.

Yang JY and Hung MC (2009) A new fork for clinical application: targeting forkhead transcription factors in cancer. Clin Cancer Res 15(3): 752-757.

Yang JY and Hung MC (2011) Deciphering the role of forkhead transcription factors in cancer therapy. Curr Drug Targets 12(9): 1284-1290. 
Shukla S, Rizvi F, Raisuddin S, Kakkar P (2014) FoxO proteins' nuclear retention and BH3-only protein Bim induction evoke mitochondrial dysfunction-mediated apoptosis in berberine-treated HepG2 cells. Free Radic Biol Med.7 (6):185-99.

Figure legends

Figure 1 Pt-1-DMCa treatment caused time-dependent inhibition of PI3K/AKT. (A) Pt-1-DMCa inhibited the Src/PI3K/PDK1/AKT signaling pathway. Cells were treated with $20 \mu \mathrm{M}$ Pt-1DMCa for various time periods as indicated and then immunoblotted for $\mathrm{p}$-Src (Tyr 416), Src, p-p85 (Tyr458), p85, p-PDK1 (Ser241), PDK1, p-AKT (Thr308) and AKT. $\beta$-Actin was probed to ensure equal protein loading. (B) Comparison of phosphorylation levels on treated cells. Quantification of the western band intensity was performed using the Image $\mathrm{G}$ software.

All data are expressed as means \pm SD of duplicates. Bars with different characters are statistically different at $\mathrm{P}<0.05$.

Figure 2 Pt-1-DMCa treatment caused time-dependent inhibition of FoxO proteins. (A) U87 cells were treated with either Pt-1-DMCa or PBS solution for the indicated time periods. Total cellular lysates were subjected to western blot analysis using antibodies against $p-$ FoxO1, FoxO1, p-FoxO3a and FoxO3a. $\beta$-Actin was used as a loading control. (B) Pt-1-DMCa treatment induced dephosphorylation of Foxo3a and its nuclear accumulation. Nuclear and cytoplasmic proteins were fractioned from Pt-1-DMCa treated U87 cells and were then subjected to western blot analysis using antibodies against FoxO3a and p-FoxO3a. B23 and $\beta$-actin were blotted to demonstrate the purity of each fraction. (C,D) Foxo3a and p-Foxo3a proteins in Pt-1-DMCa-treated or control cells were immunostained with primary antibodies and the corresponding FITC- or Cy3-conjugated secondary antibodies followed by detection using fluorescence microscopy. Green signals indicate Foxo3a, whereas red signals indicate p-Foxo3a. Nuclei were counterstained with DAPI. Representative images of each sample are presented. 
Figure 3 Pt-1-DMCa-induced inhibition of AKT directly activated FoxO3a in U87 cells, an event closely correlated with apoptosis. (A) Cells were treated with LY294002 for $1 \mathrm{~h}$ prior to Pt-1-DMCa treatment followed by treatment with either Pt-1-DMCa or PBS for $24 \mathrm{~h}$. Cells were then collected, and total cellular lysates were immunoblotted for p-AKT, p-FoxO3a, Bim and $\beta$-actin. (B) The apoptotic rate of cells was determined as described in methods section in cells transfected with AKT siRNA and treated with Pt-1-DMCa. (C) FoxO3a-mediated Pt-1DMCa-induced apoptosis downstream of AKT. Cells were transfected with FoxO3a siRNA prior to treatment with Pt-1-DMCa for $24 \mathrm{~h}$, after which time apoptotic percentage was determined. The results are statistically represented as bar graphs. $* P<0.05$ indicates statistical significance.

Figure 4 FoxO3a promoted the transcription and expression of bim, thereby enhancing apoptosis. (A, B) Pt-1-DMCa facilitated FoxO3a binding to the bim promoter. U87 cells were treated with or without Pt-1-DMCa for $24 \mathrm{~h}$ followed by subjection to the ChIP assay. The relative band intensity of PCR products revealed the binding of FoxO3a to the bim promoter. (C, D) Pt-1-DMCa increased the transcription of bim in U87 cells. Cells were treated with Pt1-DMCa for the indicated time periods followed by reverse transcription PCR and western blotting. (E) Pt-1-DMCa treatment caused the translocation of Bim from the cytoplasm to the mitochondria. Cells were treated with Pt-1-DMCa for $24 \mathrm{~h}$, and Mitotracker (red) solution was added to the medium to stain the mitochondria in cells. Cells were collected and stained with a Bim primary antibody and a FITC-conjugated secondary antibody (green). ( $F, G)$ Knockdown of Bim attenuated apoptosis in Pt-1-DMCa-treated U87 cells. Bim siRNA was used to silence the expression of bim in U87 cells that subsequently were treated with Pt-1DMCa for $24 \mathrm{~h}$. All groups of cells were analyzed using western blotting and FACS.

Figure 5 Pt-1-DMCa-induced PTEN modulated the AKT/FoxO3a/Bim signaling pathway. (A, B) Pt-1-DMCa treatment facilitated the binding of FoxO3a to the PTEN promoter. U87 cells were treated with Pt-1-DMCa for $24 \mathrm{~h}$ and then were subjected to ChIP analysis. The binding ability of FoxO3a to the PTEN promoter was calculated and analyzed.

(C) Pt-1-DMCa treatment enhanced the synthesis of PTEN mRNA through FoxO3a accumulation in the nucleus. U87 cells were treated for the indicated time periods and total cellular mRNA was then extracted and subjected to reverse transcription PCR. The PTEN mRNA level was determined and calculated from three independent experiments. The expression of PTEN was enhanced in Pt-1-DMCa-treated U87 cells. (D) Western blotting was performed to determine the expression of PTEN in U87 cells after Pt-1-DMCa treatment.

(E, F) PTEN perturbed the Pt-1-DMCa-regulated AKT/FoxO3a signaling axis. Cells were transfected with PTEN siRNA to efficiently extinguish PTEN activity. Subsequently, cells were treated with or without Pt-1-DMCa for $24 \mathrm{~h}$, and then the expression levels of $\mathrm{p}-\mathrm{AKT}, \mathrm{p}$ - 
FoxO3a, FoxO3a, Bim, and cleaved PARP were detected using western blotting. $\beta$-Actin was used as a loading control. Apoptotic effect was also determined by FACS counting.

Figure 6 ROS were involved in Pt-1-DMCa-mediated regulation of the AKT/FoxO3a/Bim signaling pathway in U87 cells. Cells samples were pretreated with NAC solution and then were treated with Pt-1-DMCa or PBS for 24 h. (A) Apoptosis was quantified by FACS.

(B) Western blot analysis of proteins extracted from U87 cells using antibodies against critical molecules as indicated. 
Figure 2

A

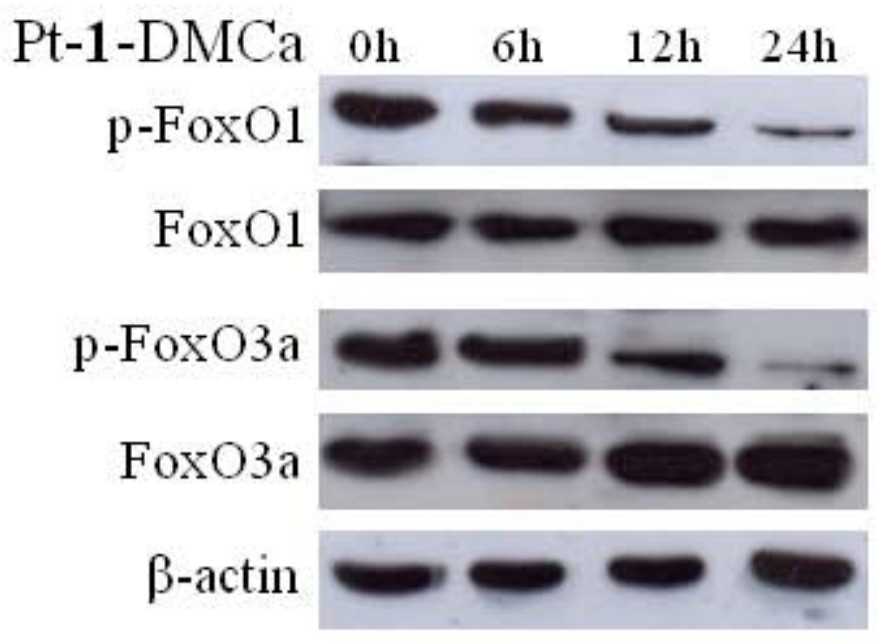

C

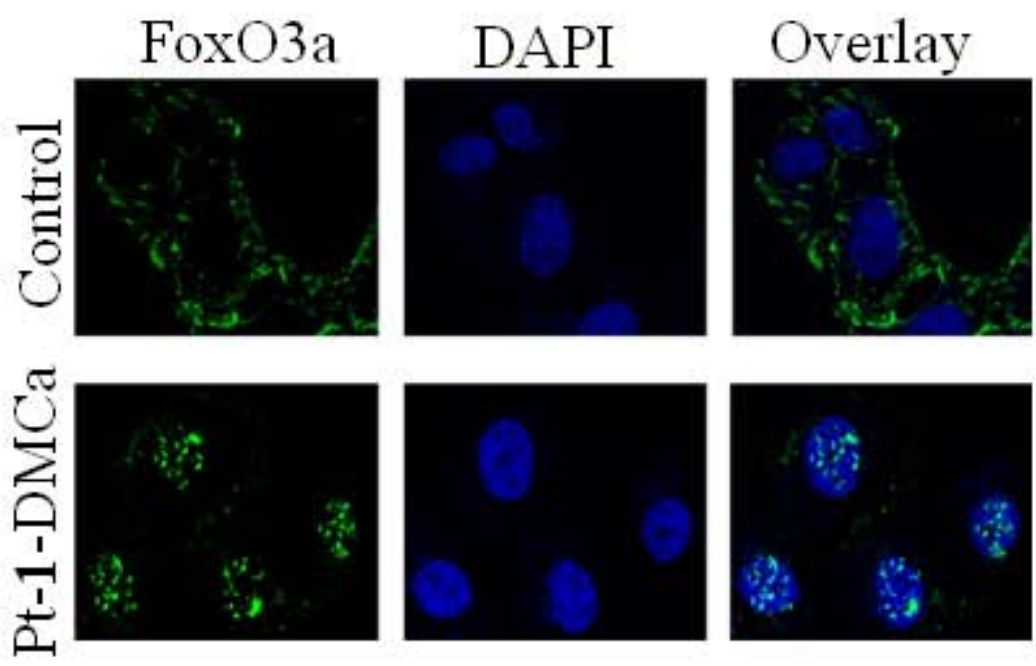

B

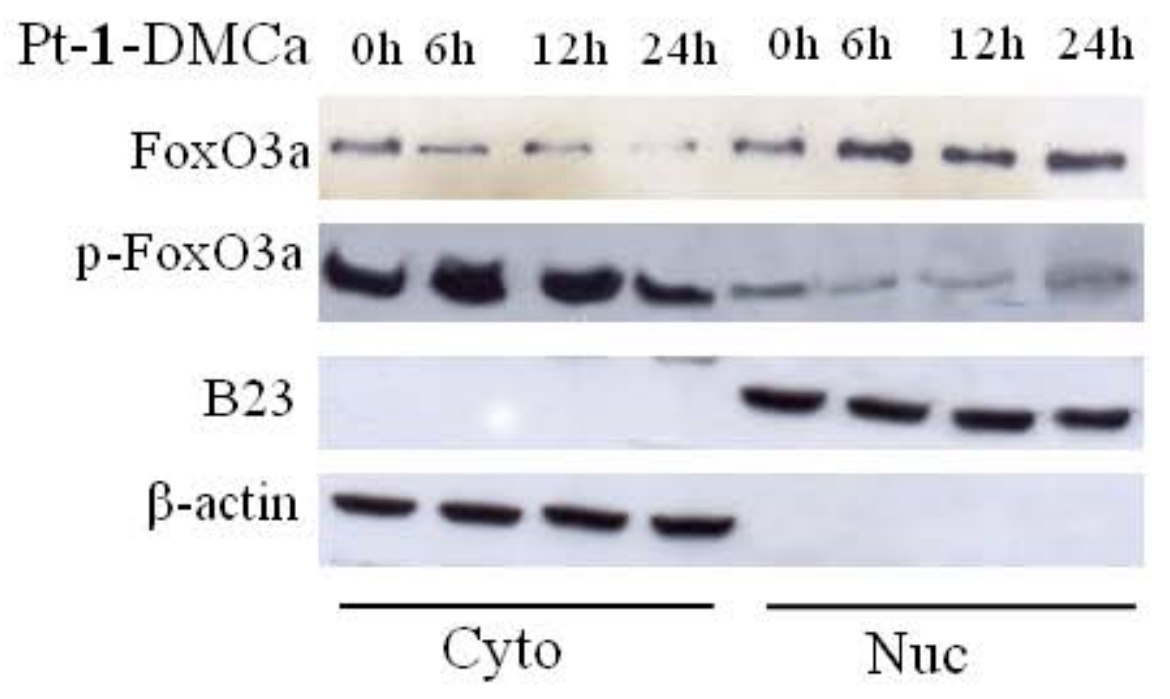

D

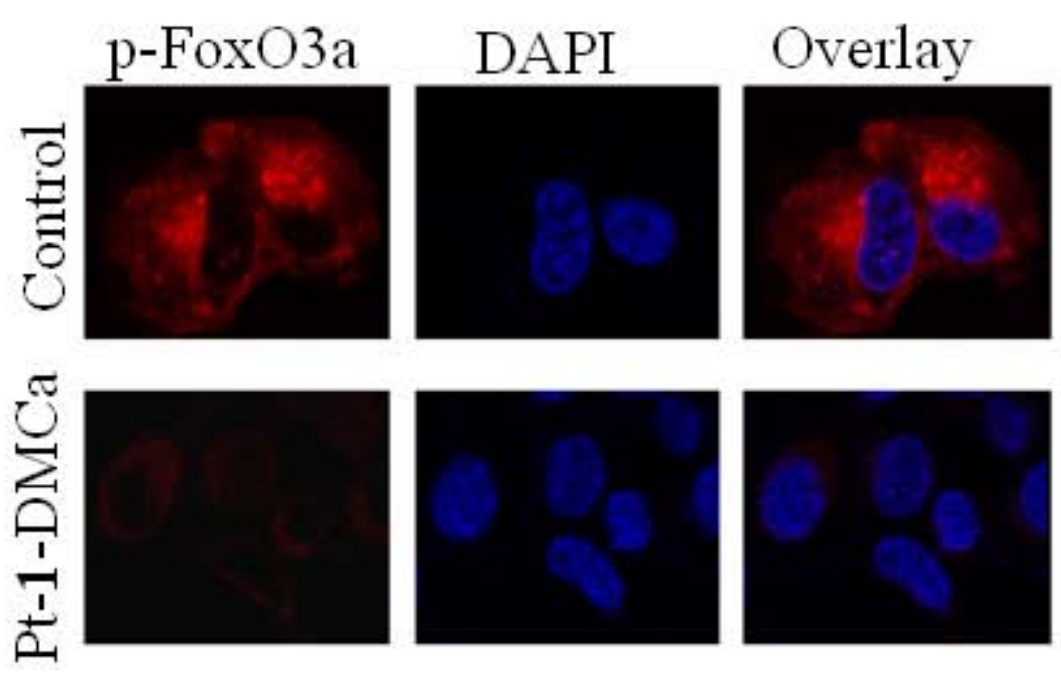


Figure 1

A

Pt-1-DMCa $0 \mathrm{~h}$ 6h $12 \mathrm{~h}$ 24h
p-Src (Tyr 416)

$\mathrm{Src}$

p-PI3K

p85 (Tyr458) PI3K

p-PDK1 (Ser 241)

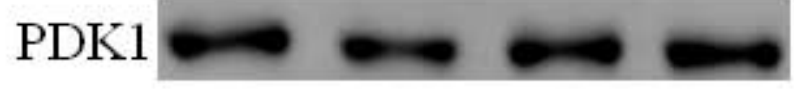

p-AKT (Thr308)

AKT

$\beta$-actin
B

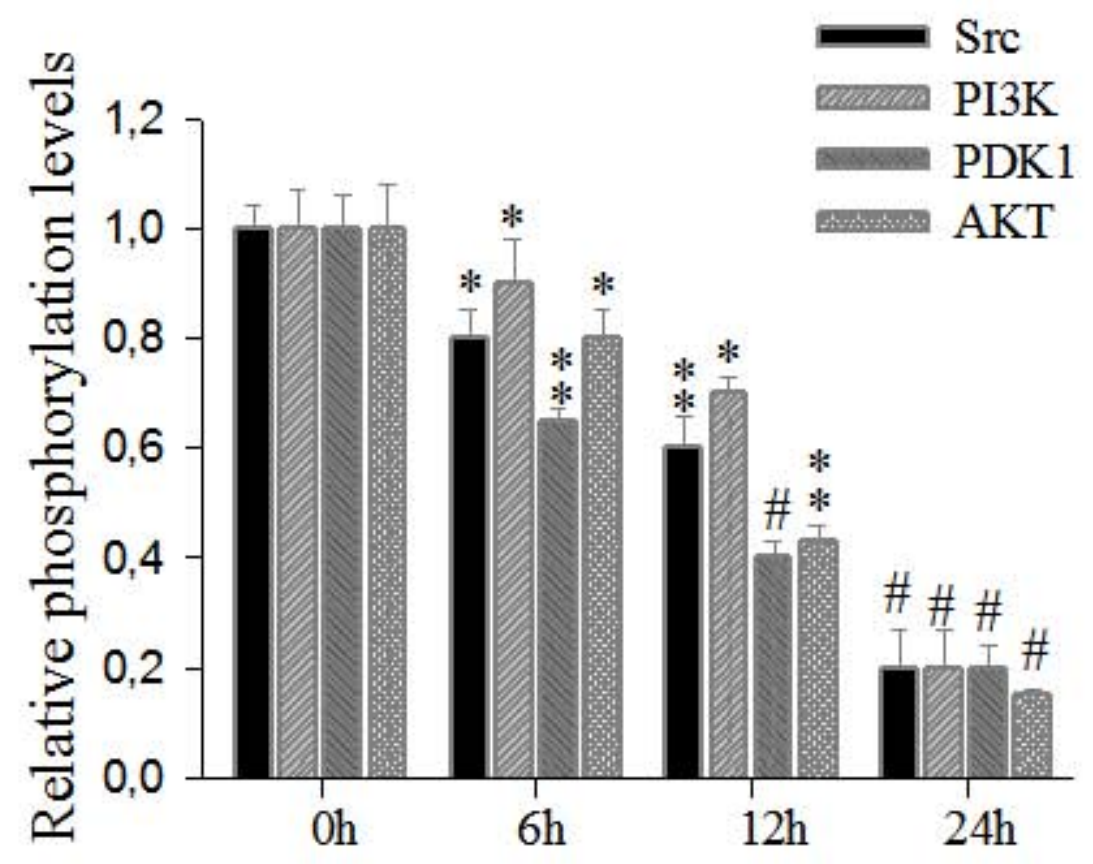


A

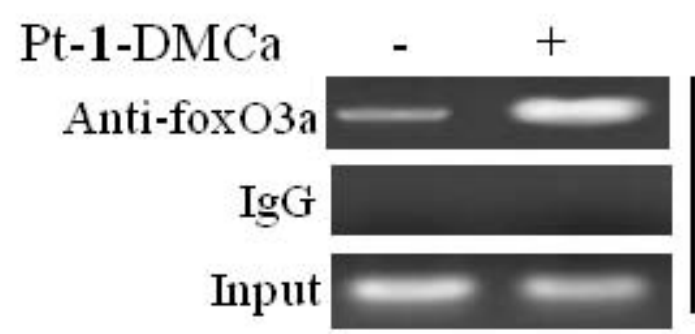

Bim

promoter

Pt-1-DMCa $0 \mathrm{~h} \quad 6 \mathrm{~h} \quad 12 \mathrm{~h} \quad 24 \mathrm{~h}$ Bim

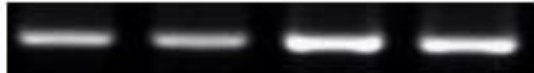

GAPDH

D

Pt-1-DMCa 0h 6h 12h 24h Bim

$\beta$-actin

$\mathbf{F}$

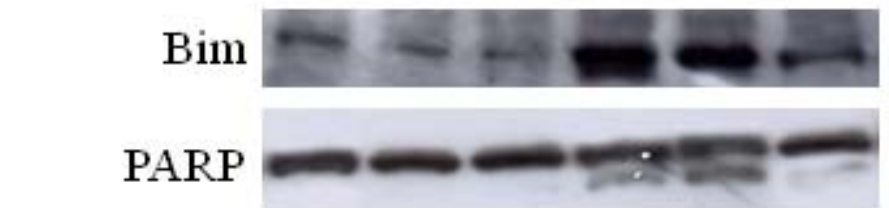

Caspase 9

C-caspase 9

$$
\beta \text {-actin }
$$

Bim SiRNA - $\quad+\quad+\quad-\quad+$ scramble siRNA - $+-\quad-+$

Pt-1-DMCa - $\quad-\quad+\quad+\quad+\quad+$
B

E
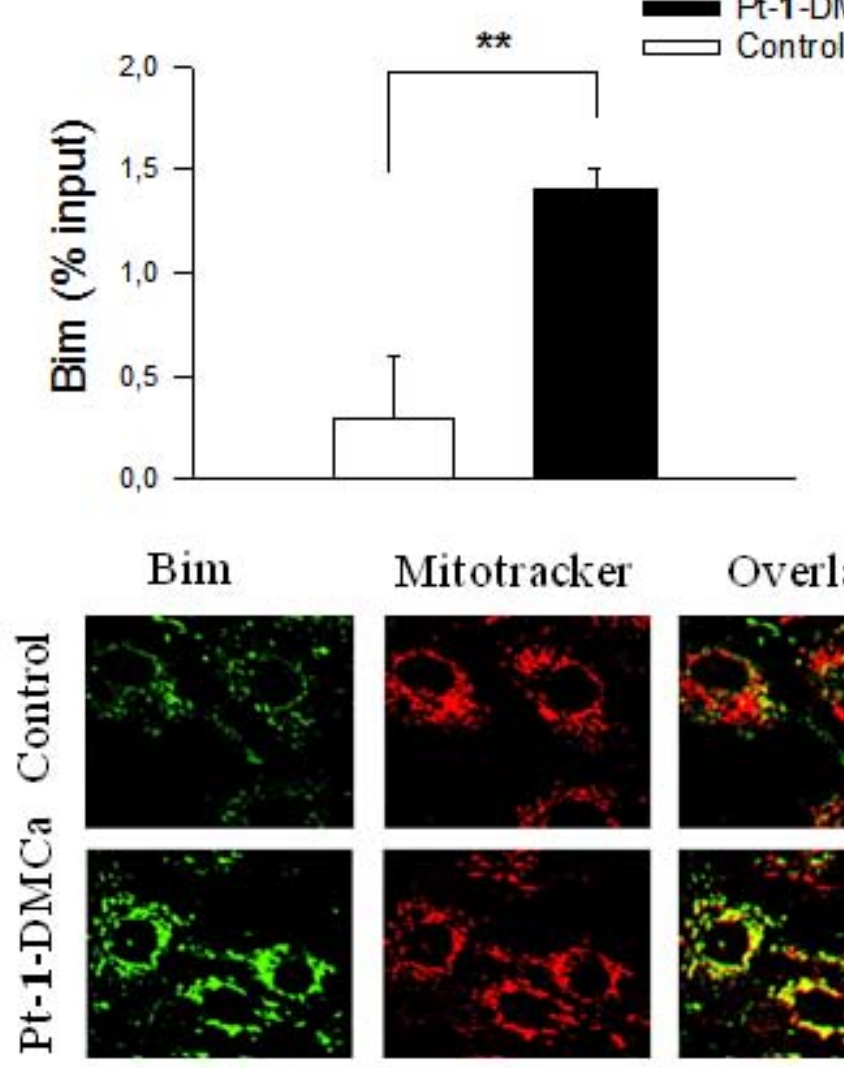

Mitotracker

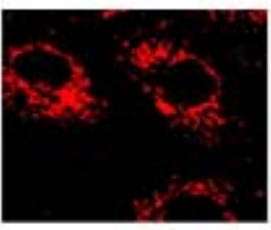

Overlay
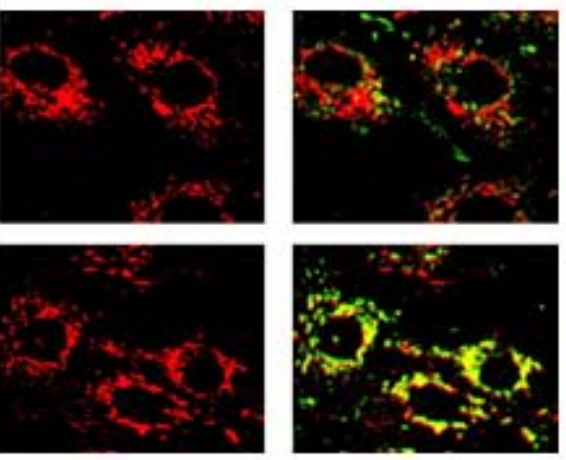

$\mathbf{G}$

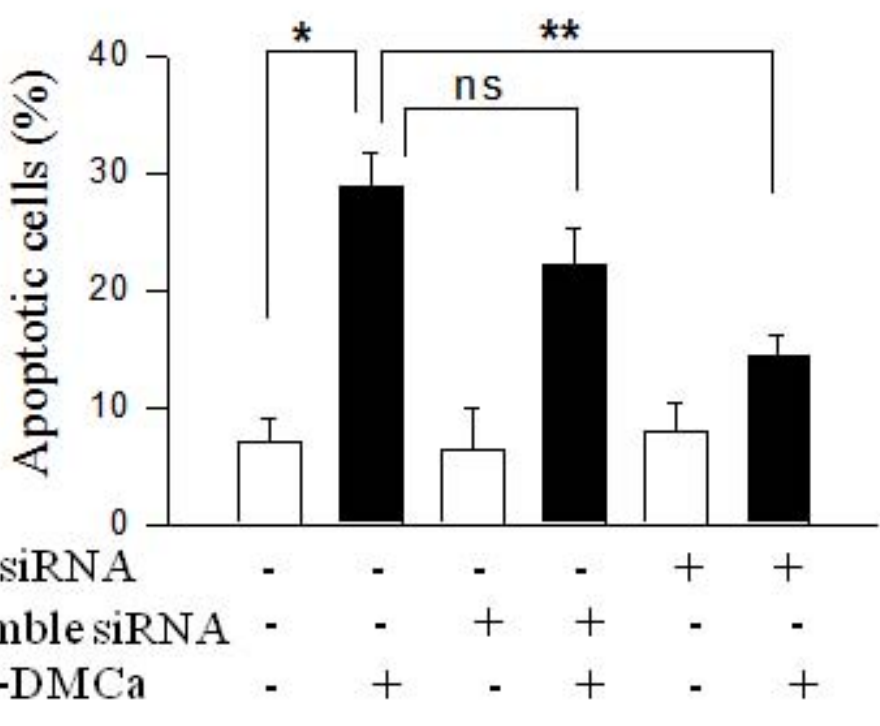


Figure 3

A

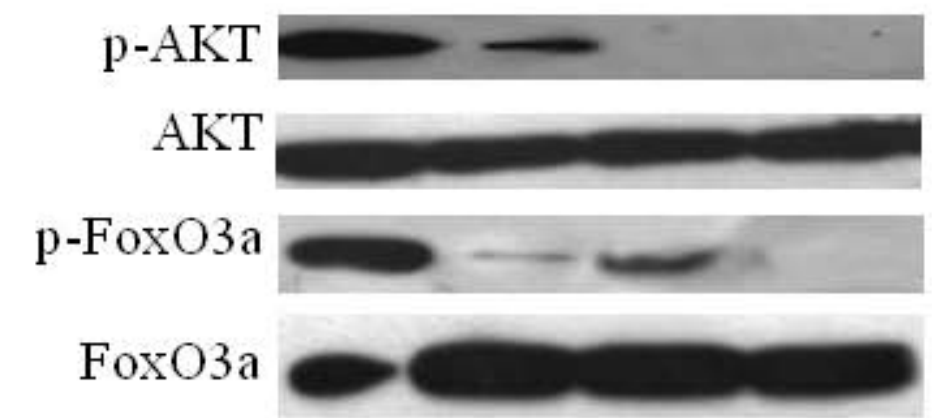

Bim

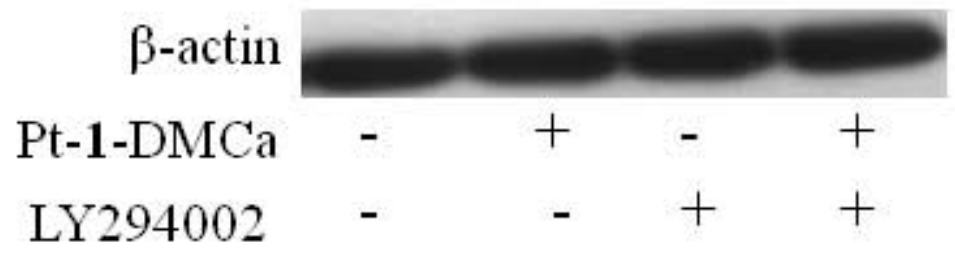

B

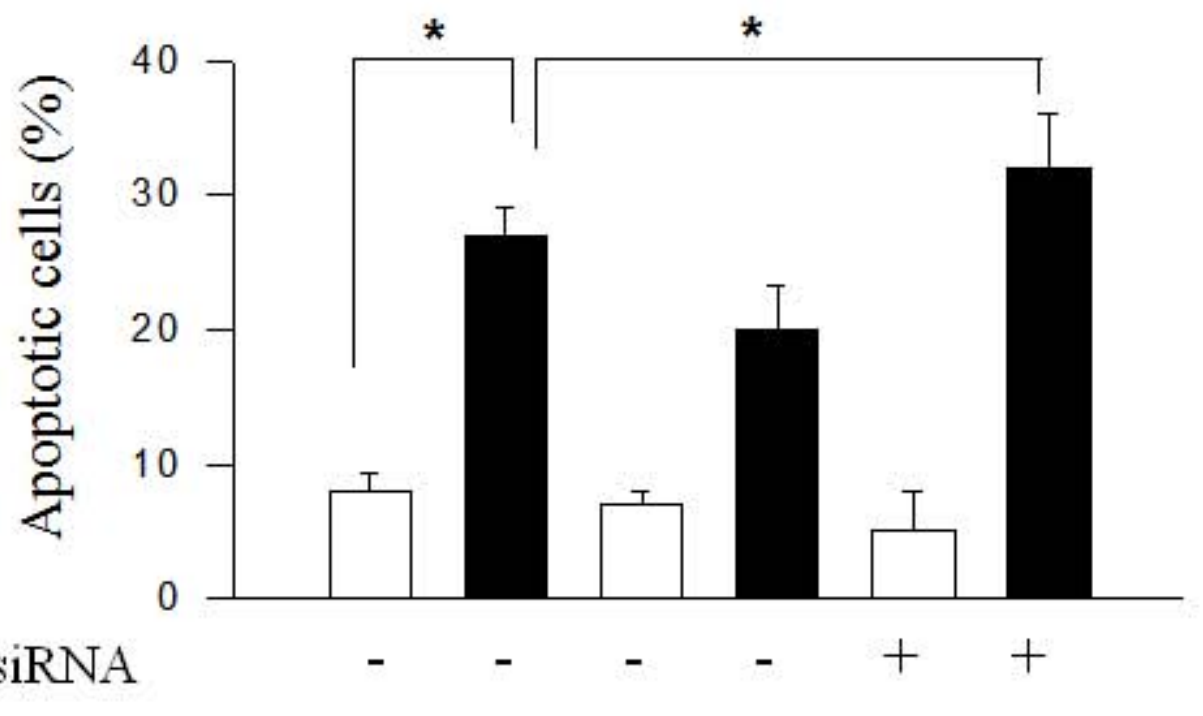

$\begin{array}{ccccccc}\text { AKT siRNA } & - & - & - & - & + & + \\ \text { scramble siRNA } & - & - & + & + & - & - \\ \text { Pt-1-DMCa } & - & + & - & + & - & +\end{array}$

$\begin{array}{ccccccc}\text { AKT siRNA } & - & - & - & - & + & + \\ \text { Pt-1-DMCa } & - & + & - & + & - & +\end{array}$

C

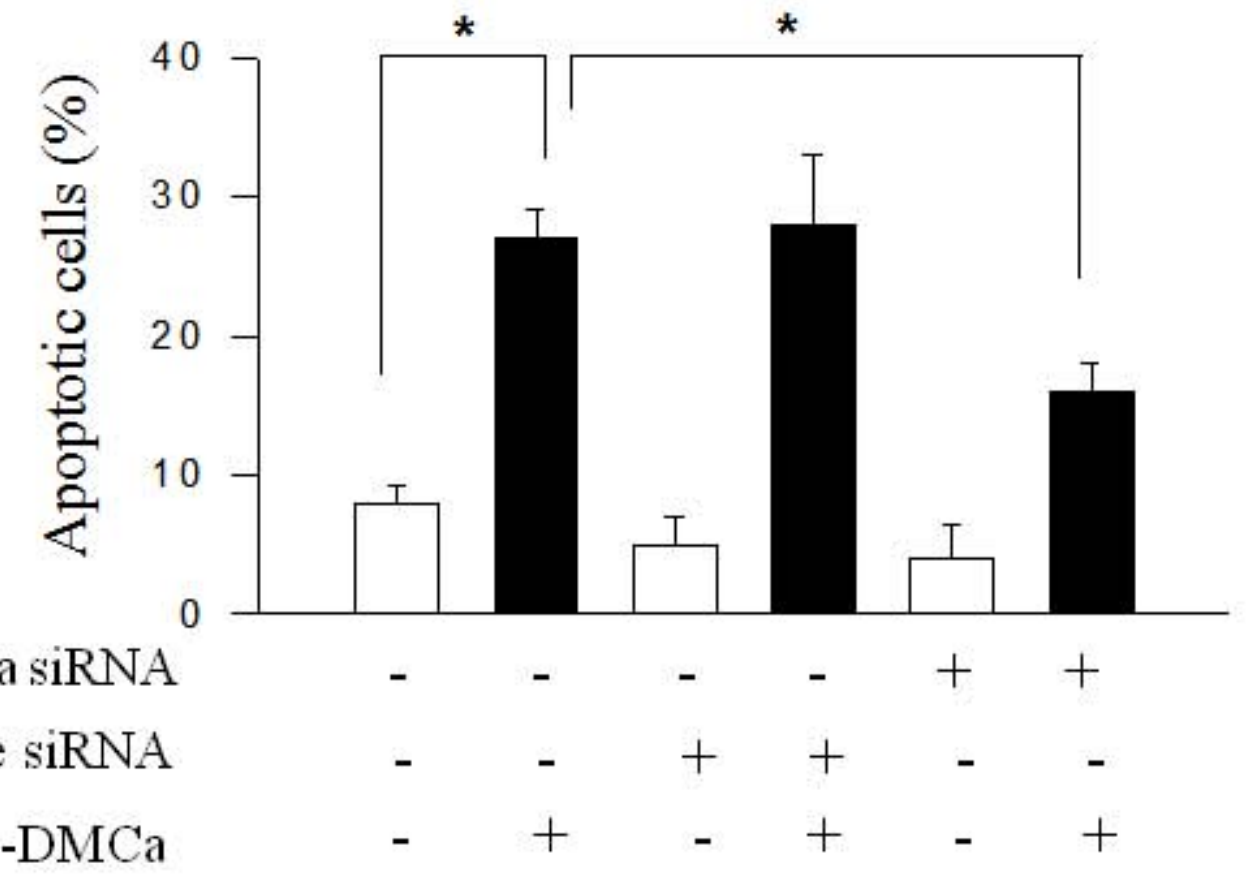

scramble siRNA

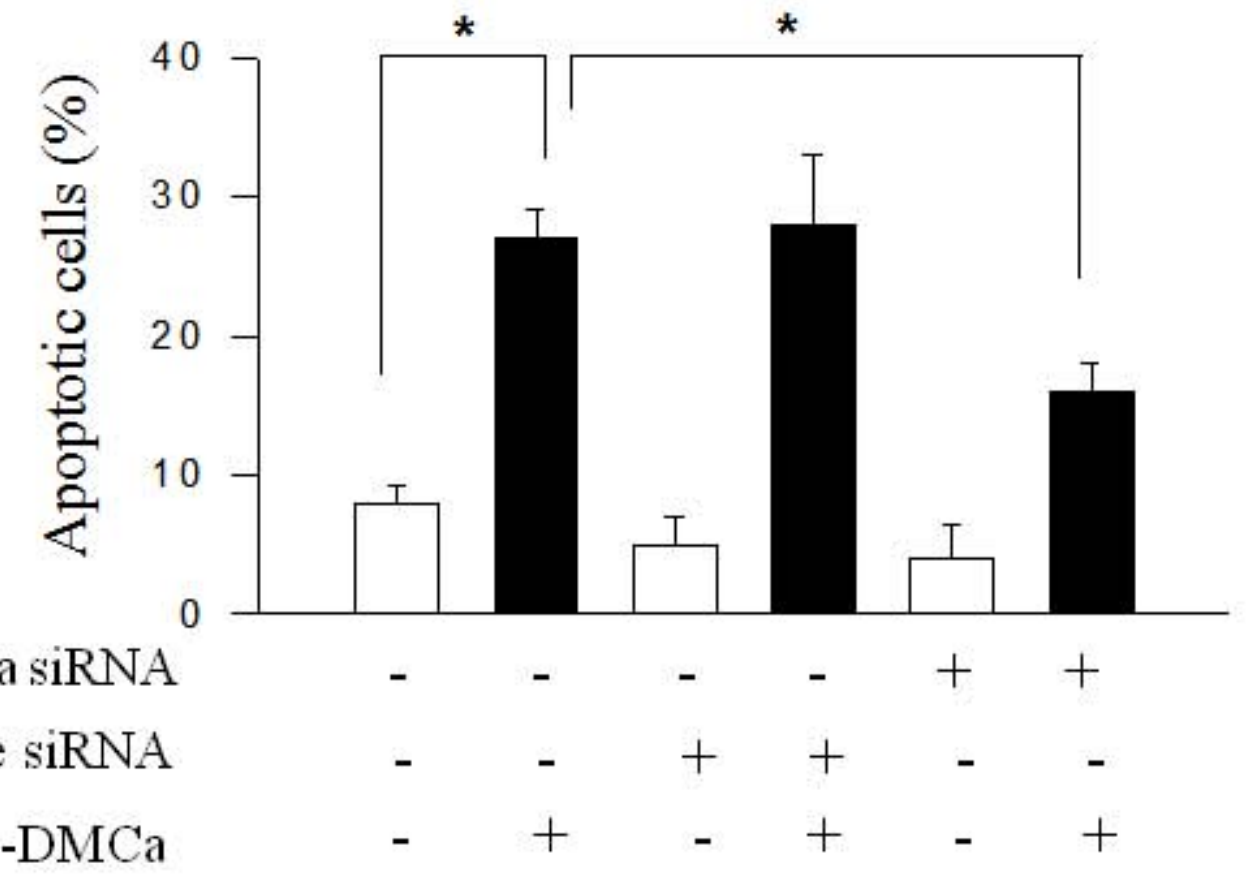

FoxO3a siRNA
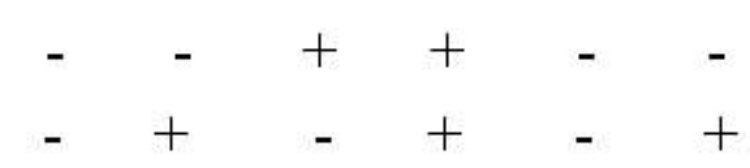
Figure 6

A

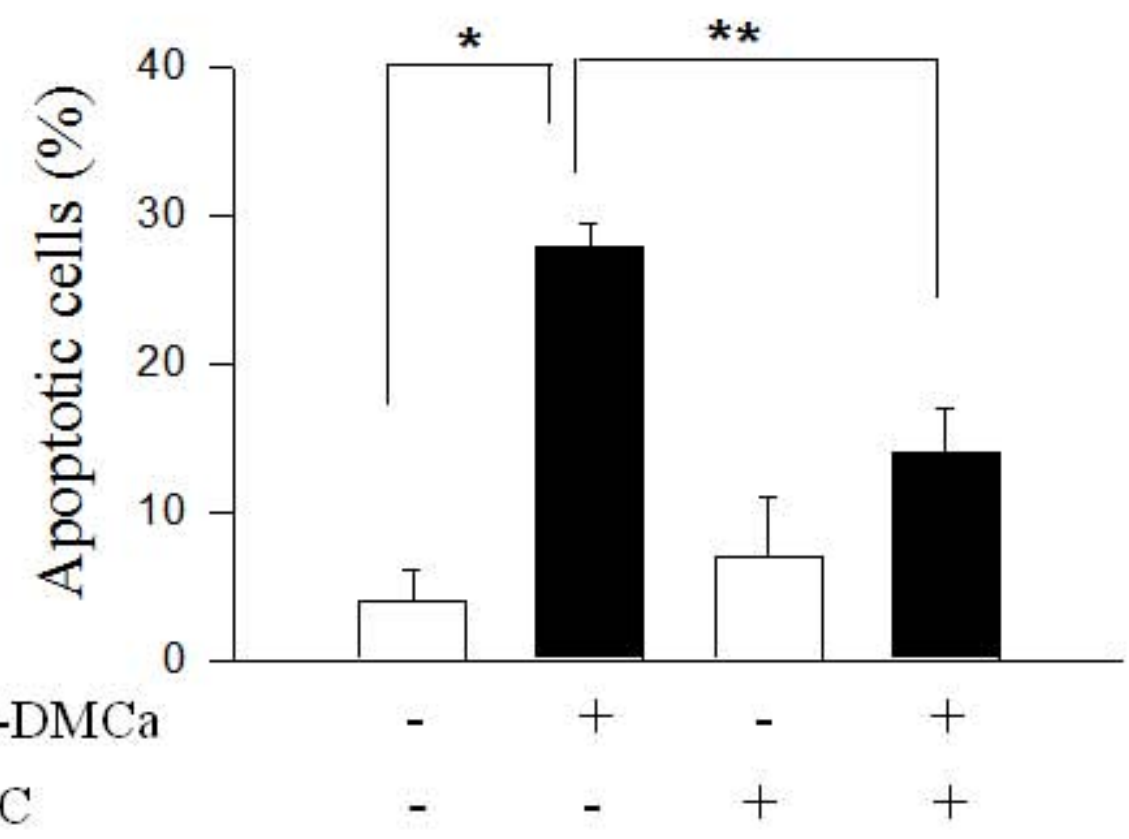

B

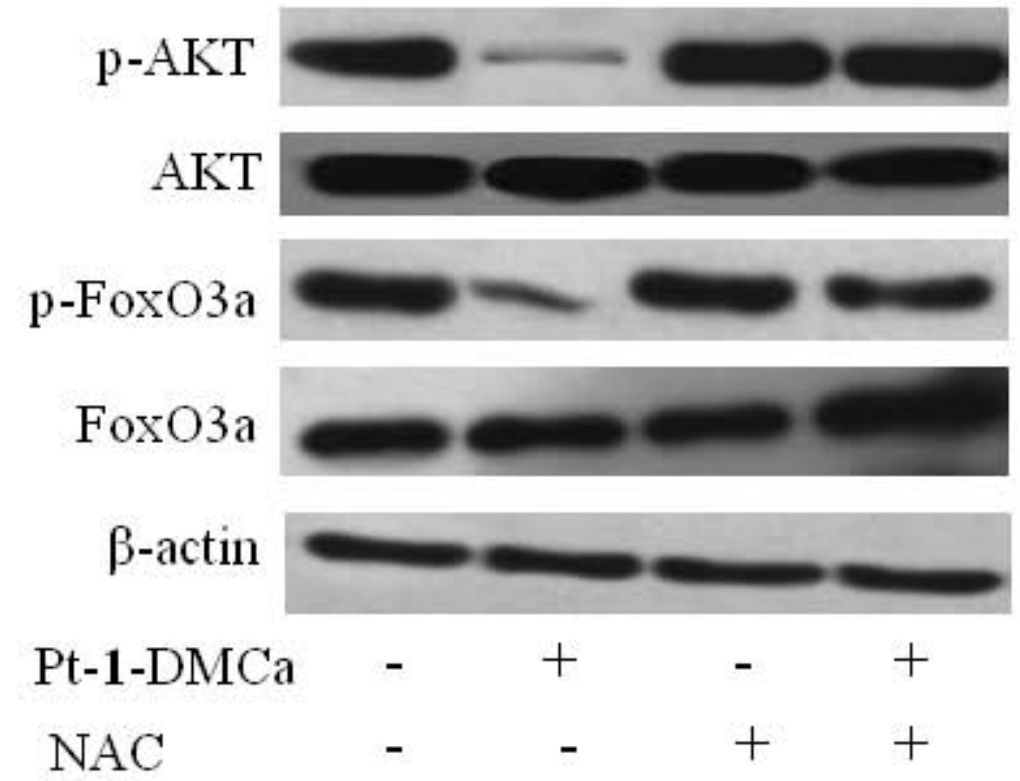


Figure 5

A Pt-1-DMCa - + Anti-foxO3a

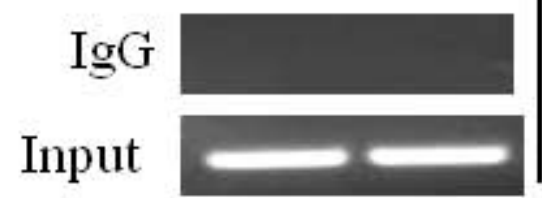

PTEN

promoter

C

Pt-1-DMCa 0 h $6 \mathrm{~h} \quad 12 \mathrm{~h} \quad 24 \mathrm{~h}$

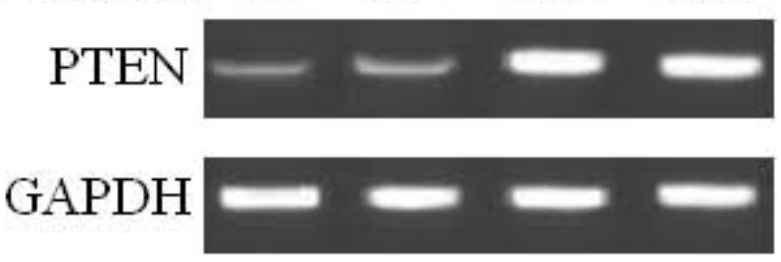

E

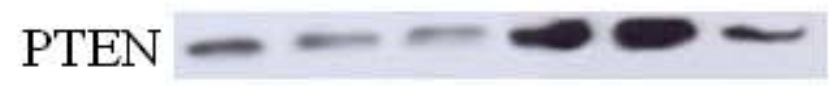
$\mathrm{p}-\mathrm{AKT}$

p-FoxO3a

Bim

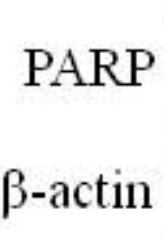

PTEN siRNA

scramble siRNA - + - - +

Pt-1-DMCa
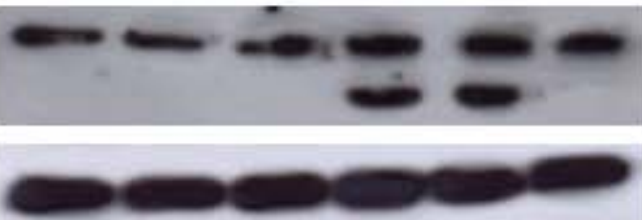

$-\quad-\quad-\quad+\quad+\quad+$
B

D
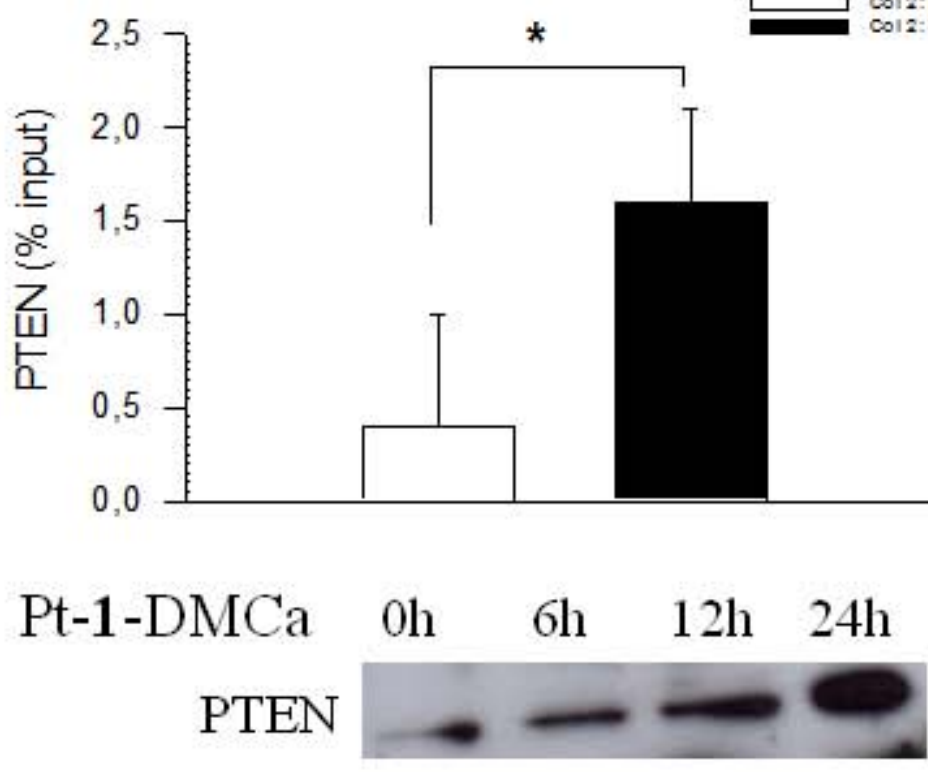

$\beta$-actin

$\mathbf{F}$

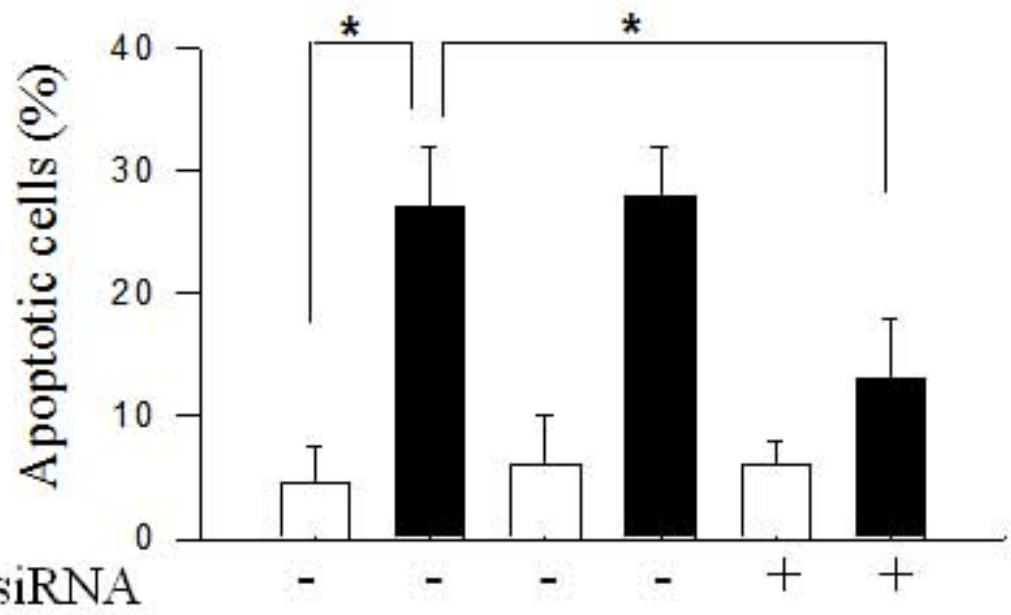

PTEN siRNA scramble siRNA Pt-1-DMCa

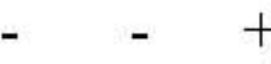

$-\quad+\quad-\quad+\quad-\quad+$ 